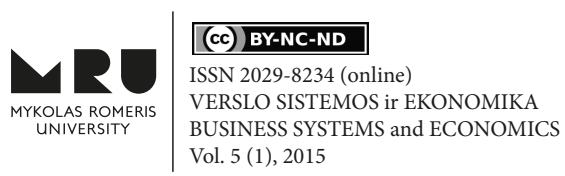

\title{
MODELING OF INTERACTION OF ECO-ECONOMIC PROCESSES
}

\author{
Mariia GRYGORKIV \\ Yuriy Fedkovych Chernivtsi National University, Department of Economics \\ Kotsubinsky str., 2, 58012, Chernivtsi, Ukraine \\ E-mail: gmvmarichka@gmail.com \\ Vasyl GRYGORKIV \\ Yuriy Fedkovych Chernivtsi National University, Department of Economics \\ Kotsubinsky str., 2, 58012, Chernivtsi, Ukraine \\ E-mail: emmvsh@gmail.com \\ Andrii VERSTIAK \\ Yuriy Fedkovych Chernivtsi National University, Department of Economics, \\ Kotsubinsky str., 2, 58012, Chernivtsi, Ukraine \\ E-mail: a.verstyak@chnu.edu.ua \\ doi:10.13165/VSE-15-5-1-02
}

\begin{abstract}
Various models of the economic structure of society are presented with an emphasis on its effect on the processes of eco-economic interaction. The models belong to the type of simulated models describing the dynamics of economic structure indicators, prices and pollution. The models can be used for exploring the patterns and consequences of ecological and economic systems and their social orientation.
\end{abstract}

Keywords: economic structure of society, simulated models, ecological economics, pricing, eco-economic system, eco-economic interaction.

JEL Classification: C21, C22, E17.

\section{Introduction}

The modern world is characterized by many challenges of civilized nature. One of such problems is the interaction between economics and ecology both within individual countries and any local or cross-border region of global scale, because the main polluter of the environment is the economic activities of human society, due to not only the unsustainable use of natural resources (especially non-renewable resources), but also to the production of many kinds of environmentally hazardous products, as well as inadequate amounts of consumption of the products, not necessarily environmentally harmful. Economics and ecology have been coming into a conflict for a long time because the interests of each component are often heavily opposed, so the problem of economic-ecological interaction and sustainable development must be built on the base of a socially oriented and ecologically balanced economy. 
The awareness of the severity and urgency of the problem in the end of the 20th century resulted into many significant events, particularly The United Nations Conference on Environment and Development, also known as the Rio Summit, Rio Conference, and Earth Summit that was a major United Nations conference held in Rio de Janeiro from June 3 to June 14 in 1992 (UNCED, 1992).

The issues addressed included:

- $\quad$ systematic scrutiny of patterns of production - particularly the production of toxic components, such as lead in gasoline, or poisonous waste, including radioactive chemicals;

- alternative sources of energy to replace the use of fossil fuels which are linked to global climate change;

- new reliance on public transportation systems in order to reduce vehicle emissions, congestion in cities and the health problems caused by polluted air and smoke;

- $\quad$ the growing scarcity of water (UNCED, 1992).

An important achievement was an agreement on the Climate Change Convention which, in turn, led to the Kyoto Protocol. Another agreement was to "not carry out any activities on the lands of indigenous peoples that would cause environmental degradation or that would be culturally inappropriate". There were other events that showed that the problem of economic-ecological interaction had become a special social significance in the modern world.

The successful solution of the described problem is impossible without its fundamental investigation allowing developing the conceptual, methodological and methodical approaches to real greening of the economics and its social purpose. An important role among scientific methods of the investigation of the complex economic-ecological systems belongs to economic modeling. The paradigm of the linking of sub-models of economics and social science with sub-models of ecology has not been achieved (Jeffers, 1987). At best, a few economic or social variables have been incorporated into ecological models, or, conversely, a small number of ecological variables have been incorporated into economic and social models. The link between ecological sub-models in their full and necessary complexity and economic and social sub-models, at their own level of complexity, has still to be made (Jeffers, 1987).

The range of research on this subject in the world of scientific literature is quite extensive, so to make a detailed review of even major publications and their results in the framework of this article is impossible and impractical. But there are some schools of ecological-economic interaction modeling of which we will address ourselves. First, it is worth noting the publications of economic and mathematical modeling of Ukrainian scientific school, which includes I. Lyashenko (Lyashenko, 1994, 1999, 2010), M. Mihalevich (Mihalevich, 1994, 2005), V. Grygorkiv (Grygorkiv, et al., 2004, 2007, 2008), A. Onishenko (Onishenko, 2011), L. Buyak (Buyak, 2008), A. Verstiak (Verstiak, 2008), R. Biloskurskiy (Biloskurskiy, 2007), O. Yakutova (Yakutova, 2004) and others. Most of the results of these scientists associated with the development and optimization of the balance between ecological and economic models. Important results in the field of ecological and economic modeling belong also to a Russian scientific school: A, Petrov, I. Pospelov and A. Shananin (Petrov, et al., 1996).

The aim of the research is to develop one-sector models of ecological-economic interaction in the space of parameters of the economic structure of society, the market price of the aggregate social product and environmental pollution. 


\section{One-sector models of ecological-economic interaction}

The authors of the present research define the economic structure as the distribution of society elements (such as families) by liquid savings in money and (or) in securities that to be fast and lossless converted into money (Grygorkiv, 2012). The indicators of economic structure are the quantities of liquid accumulations of different social groups (separate social clusters), hereinafter referred to as the savings. The concept of aggregate social product is common in the literature of economics, and so is the corresponding market price for it. The indicator of pollution is the amount of uncompensated (unused) pollutants that are emitted into the environment. These indicators form the corresponding phase space, which points at the time describe the possible states of the research object.

Let us consider one-sector economics where the main aggregate product is produced and simultaneously utilization of industrial residues (waste) is carried. Consider the model of society where the economic structure is reflected in three groups (clusters) of citizens: $G_{0}$ - pensioners, $G_{1}$ - all members of society involved into social and economic activity, $G_{2}$ - owners of the companies producing the aggregate social product. Let us assume that $n_{i}$ is the total number of citizens in groups $G_{i}$, and $z_{i}$ - their liquid savings $(i=\overline{0,2})$ to be spent on the purchase of an aggregate product with the price $p_{A}\left(\alpha_{i} z_{i}\right)$, on the elimination of waste of socio-economic activity with rate $p_{B} \quad\left(\beta_{i} z_{i}\right)$ and on the needs of these activities, in particular - on production needs $\left(\gamma_{i} z_{i}\right)$. It is clear that $\alpha_{i}+\beta_{i}+\gamma_{i} \leq 1$ $\left(\alpha_{i} \geq 0, \beta_{i} \geq 0, \gamma_{i} \geq 0\right)$. Considering the fact that the first two clusters are economically inactive and $G_{2}$ is economically active, it can be assumed that $\beta_{i}=\gamma_{i}=0$ for $i=\overline{0,1}$. Another fundamental assumption concerns the "equivalence" of each member of the society inside the cluster, in other words, every member of the "averaged" society reflects his group and has the same purchasing power $\alpha_{i} z_{i} / p_{A}(i=\overline{0,2})$, the production capacity per one person employed $n_{2} \gamma_{2} z_{2} / n_{1} p_{A}$ and the ability to the disposal of environmentally hazardous resi-

dues (capacity utilization) $n_{2} \beta_{2} z_{2} / n_{1} p_{B}$.
Let us consider that the demand of each consumer is equal to $q\left(\frac{\alpha_{i} z_{i}}{p_{A}}\right)$, where $q-$ demand function $(i=\overline{0,2})$, the amount of the aggregate product produced by one worker (employee) in the group $G_{1}$ is equal to $f\left(\frac{n_{2} \gamma_{2} z_{2}}{n_{1} p_{A}}\right)$, where $f$-production function, and the amount of recyclable pollution items of the same employee in the group $G_{1}$ is equal to quantity $\varphi\left(\frac{n_{2} \beta_{2} z_{2}}{n_{1} p_{B}}\right)$, where $\varphi$ - waste utilization function. At the macroeconomic level, particularly in the case of a single aggregate sector, the manufacturer must waste utilization of its activities and it should be supervised by the relevant regulatory authority (government, NGOs, etc.). One of the conditions of such regulation may be the following condition:

$$
\lambda f\left(\frac{n_{2} \gamma_{2} z_{2}}{n_{1} p_{A}}\right)-\varphi\left(\frac{n_{2} \beta_{2} z_{2}}{n_{1} p_{B}}\right)=\theta^{*},
$$

where $\theta^{*}$ - maximum value (generally dynamic) of no eliminated pollution created by one worker $G_{1}, \lambda(0<\lambda<1)$ - percent of pollution in the aggregate product.

The dynamic equations of (capital) savings of social groups $G_{0}, G_{1}, G_{2}$ representatives are formed on the basis of the assumption that the average (and, thus, the limit) in- 
crease of savings is directly proportional to the difference between revenues and costs of each in time. As pensioners receive a pension that is not taxable and workers -- wages, the dynamic equation of their savings are of the following form:

$$
\frac{d z_{i}}{d t}=s_{i}\left(1-k_{0}^{(i)}\right)-p_{A} q\left(\frac{\alpha_{i} z_{i}}{p_{A}}\right), i=\overline{0,1},
$$

where $k_{0}^{(i)}$ - income tax rate $\left(k_{0}^{(0)}=0\right), s_{i}$ - income (salary or pension) in a monetary unit.

Revenue of a representative in group $G_{2}$ consists from taxable value of sales to all members of society and the costs associated with the personal consumption of the aggregate product, waste utilization in terms of ecological and economic balance [1], taxable (rate $k_{1}$ ) expenditure on wages to engaged members of group $G_{1}$, value added tax (rate $k_{2}$ ) and internal needs of industrial activity (part $\lambda^{*}$ ) that are also part of the added value. In other words, the dynamic equation of savings $z_{2}$ is formalized as:

$$
\begin{aligned}
& \frac{d z_{2}}{d t}=\frac{p_{A}}{n_{2}}\left(1-k_{0}^{(1)}\right) \sum_{i=0}^{2} n_{i} q\left(\frac{\alpha_{i} z_{i}}{p_{A}}\right)-p_{A} q\left(\frac{\alpha_{2} z_{2}}{p_{A}}\right)- \\
& -p_{B} \frac{n_{1}}{n_{2}}\left[\lambda f\left(\frac{n_{2} \gamma_{2} z_{2}}{n_{1} p_{A}}\right)-\theta^{*}\right]-\frac{n_{1}}{n_{2}} s_{1}\left(1+k_{1}\right)-p_{A} \frac{n_{1}}{n_{2}}\left(k_{2}+\lambda^{*}\right) f\left(\frac{n_{2} \gamma_{2} z_{2}}{n_{1} p_{A}}\right) .
\end{aligned}
$$

Prices $p_{A}$ and rate $p_{B}$ also belong to the dynamical variable of the model. Changes in time of these variables depend on the difference between supply and demand of the appropriate basic aggregate product and pollution, so the equation for $p_{A}$ and $p_{B}$ is the following:

$$
\begin{aligned}
& \frac{d p_{A}}{d t}=\theta_{A}\left[\sum_{i=0}^{2} n_{i} q\left(\frac{\alpha_{i} z_{i}}{p_{A}}\right)-n_{1} f\left(\frac{n_{2} \gamma_{2} z_{2}}{n_{1} p_{A}}\right)\right], \\
& \frac{d p_{B}}{d t}=-\theta_{B} n_{1} \theta^{*},
\end{aligned}
$$

where $\theta_{A}$ i $\theta_{B}$ - constant rates of price and rate regulation.

Since the ratio [2]-[5] is a system of differential equations, it should be supplemented by initial conditions (values of dynamic variables on the initial time of the simulation $t=0$ ):

$$
z_{i}(0)=z_{i}^{(0)}(i=\overline{0,2}), p_{A}(0)=p_{A}^{(0)}, p_{B}(0)=p_{B}^{(0)} .
$$

Set (2)-(6) is one of the models of one-sector Ecological Economics in the space of economic structure indicators, the prices on aggregate product and waste utilization.

This model has a number of modifications; in particular, it can be supplemented by the equations of the dynamics of no wasted pollution:

$$
\frac{d \xi}{d t}=n_{1} \theta^{*}-\eta \xi
$$




$$
\xi(0)=\xi^{(0)},
$$

where $\xi$ - dynamical variable that describes the total amount of environmental pollution, and $\eta \quad(0<\eta<1)$ - constant index of pollution assimilation. So, taking into consideration [7], [8], the model [2[-[8] is obtained. Without dwelling on other versions of the models of this type, some of the results of the qualitative and experimental analysis of the above mentioned models are described.

\section{Empirical evidence}

Let us return to equation [3] describing the dynamics of representative capital in group $G_{2}$ (owners and others). Considering the value of other dynamic variables ratio (2)-(8) as constant (over a period of time), the availability and nature of equilibrium states are found out if $d z_{2} / d t=0$, i.e., the right part of equation (3) equals to zero (it can be written as $A(s)-B(s)=0$, where $s=z_{2} / p_{A}, A(s)$ - income, $B(s)$ - costs). Typically, organizational and operational costs in the economy occur so that the amount of product is approximately equal to the demand for it. It means that in practice functions $A(s)$ and $B(s)$ have similar values and are intersected. The points of intersection actually describe the possible equilibrium states in the economy. Figure 1 shows six highest possible non-trivial solutions of the equation $A(s)=B(s)$ in the case when demand functions and production functions refer to appropriate classes of functions described by Chernavskii (Chernavskii, 2002).

Figure 1: Schematic illustration to the graphical solution of the equation $A(s)=B(s)$

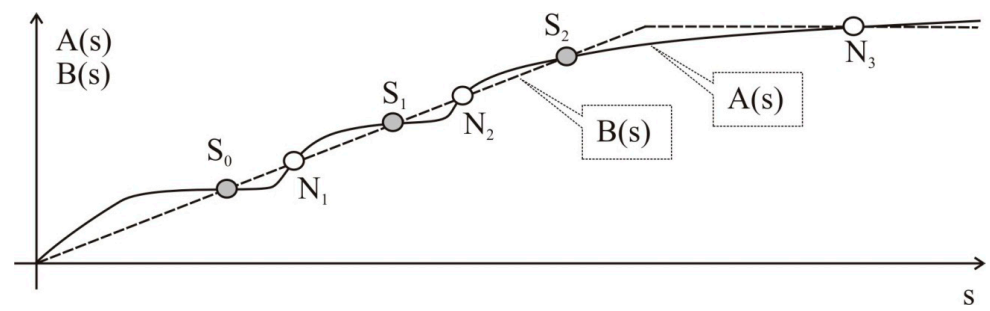

Source: created by the authors

These solutions differ by the financial capacity of product manufacturer and, thus, by the ability of the consumer. The equilibrium points $S_{0}, S_{1}, S_{2}$ are steady and the points $N_{1}, N_{2}, N_{3}$ - unsteady. Indeed, any deviation from the points $S_{0}, S_{1}, S_{2}$ to the left is economically inappropriate because it means a production reduction for an existing demand. The deviations to the right are also undesirable because it means an increasing production while reducing the demand. Thus, any deviation from the economic system $S_{0}, S_{1}, S_{2}$ leads to a situation in which the system returns back to these points. The points $N_{1}, N_{2}, N_{3}$ have a quite different character. Any displacement of these points to the left means layoffs and reducing demand, whereas any displacement to the right - output growth with the increasing demand that the economic system does not return to these points after rejection from them. Obviously, the excess demand (the difference between supply and demand) changes its sign from "+" to “-” in a steady state and from “-” to “+” in an unsteady state. 
In addition, a significant effect on the parameters of the equilibrium states of demand functions and especially of production and utilization functions reflecting technological progress in the production of an aggregate product should be noted. Depending on the level of technology productivity, some states may disappear. For example, if states $N_{3}$ and $S_{2}$ disappear (to the right from the point $N_{2}$, graph $B(s)$ is located lower from graph $A(s)$ ), then the economy may have only two low production states $\left(S_{0}, N_{1}\right)$ and two high production $\left(S_{1}, N_{2}\right)$ states. If after the point $N_{1}$ graph $B(s)$ is located lower from graph $A(s)$, then we have low production economics (for example, backyard production), and if after the point $S_{0}$ graph $B(s)$ is located lower from graph $A(s)$, then a single point of stable equilibrium $S_{0}$ will reflect the minimum level of productivity and sustainable utilization of pollutants in backyard production. The situation when graph $B(s)$ has the only single zero point of intersection with the graph $A(s)$ describes the production, consumption and waste pollution in natural production when manufacturers produce a product only for their own needs. Obviously, some equilibrium states are harmful to society, causing acute social polarization (distance values $A(s)$ from $B(s)$ ).

Financial viability of the manufacturer (in group $G_{2}$ ) can be evaluated as an integral indicator:

$$
V(s)=\int_{0}^{s} D(x) d x=\int_{0}^{s}(A(x)-B(x)) d x,
$$

It characterizes the effective demand and ability to pay for the production of an aggregate product and recycling of pollutants. This index is useful for qualitative model analysis. It can be stated that $V^{\prime}(s)=D(s)=A(s)-B(s)$, implying from the definition of the indicator $V(s)$, i.e., the solvency $V(s)$ may have extreme points in the equilibrium point $(A(s)=B(s))$. Experimental evidence with models (2)-(6), (2)-(8) show that function $V(s)$ reaches minimum points in a stable equilibrium and maximum points in an unstable equilibrium.

The economic structure of society depends not only on the features of economic behavior. It depends on the financial costs of all participants in the economics, as well. The influence $\beta_{2}$ on solvency $V(s)$ shows that increasing of $\beta_{2}$ causes local minimal displacement of the indicator $V(s)$ to the right along the abscissa $s$ and down along the ordinate $V$. This ultimately creates a situation where some companies may have motivation for the selection in a separate sector - the sector wasting pollution (in this sense, the regulatory relationship [1] has a special importance).

The processes of ecological-economic interaction is strongly dependent on particle $\beta_{2}$ and $\gamma_{2}$. The relationship between these particles in one-sector economics should be regulated outside (the role of the restrictions [1]). The increasing of $\gamma_{2}$ does not cause the formation of singular points of the index $V(s)$, but confirms the general pattern of the economics, whereby the growth of capital leads to a higher participants productivity, particularly through the effective demand of employees in group $G_{1}$.

The sharp increase in the costs of private consumption (share $\alpha_{2}$ ) has harmful consequences for the whole economics and for the processes of ecological economics.

The formation rates $p_{A}$ of an aggregate product can be investigated using the integral indicator: 


$$
V_{A}(s)=\int_{0}^{S} Q_{A}\left(z_{2}\right) d z_{2}
$$

where $Q_{A}\left(z_{2}\right)$ - the right part (4). With $\frac{d p_{A}}{d t}=0$, we have $Q\left(z_{2}\right)=0$ or $V_{A}^{\prime}(s)=Q_{A}(s)=0$ , i.e., the equation roots $Q_{A}(s)=0$ coincide with the extreme points of function $V_{A}(s)$, where the equilibrium price is constant. The investigation of $V_{A}(s)$ confirmed that equilibrium prices exist in ecological and economic system, described by the equation (2)-(6) or (2)-(8).

A similar conclusion can be drawn regarding the tariff $p_{B}$, investigating the function behavior $V_{B}(s)=\int_{0}^{S} Q_{B}\left(z_{2}\right) d z_{2}$, where $Q_{B}\left(z_{2}\right)$ - the right part of [5]. Thus, the fact can be confirmed that funding for primary production should be consistent (balanced) with the disposal of pollutants taking place in Ecological Economics.

\section{Conclusions}

The models proposed in this paper allow studying the actual processes of ecologicaleconomic interaction in the space of parameters of the economic structure of society, the price of aggregate social product, the tariff for wasting and undestroyed (unused) pollution. Qualitative and experimental analysis of the models is done by using input indicators of solvency detecting equilibrium states (stable and unstable) in ecological economics' system and establishes their dependence on the main parameters of models. The analysis of dependence of producer solvency from the structure of financial expenditure showed that increasing the costs for processing pollutants (residues of production and other economic activities) contributes to the formation of a new sector involving only waste utilization. The analysis of the integral index of aggregate product prices depending on the ratio between supply and demand (taking into account the balance of income of the company owner and its costs) confirmed the existence of dynamic equilibrium where the price and production capital dynamically balanced with the income and expenses of the manufacturer, including costs for the ecology in its activities.

The introduced rate of utilization capacity in one-sector economics also revealed equilibrium states where the production costs of the main product balanced with waste disposal costs for primary production and establish a balanced match between financial security of primary production and recycling process.

In general, qualitative and experimental analysis of the models, using indicators of solvency, enables in the real situation (i.e., with specific values of model parameters identified for the economy of a particular region or country) to develop practical recommendations for the development of the economics in a dynamic ecological-economic balance. 


\title{
References
}

Chernavskii, D., Starkov, N., and Scherbakov, A. (2002). The Problems of Physical Economy. Success of Physical Science, 9(172): 1045-1066.

Grygorkiv, M. (2012). Simulation-dependent Financial Capacity Functions of Economic Behavior. Galician Economic Journal, 2(35): 114-123.

Grygorkiv, V. (2009). Economic Modeling: A Tutorial. Chernivtsi: Chernivtsi National University, p. 320.

Grygorkiv, V. S., and Biloskurskii, R. R. (2007). Some Stochastic Leontief-Ford Models and Their Deterministic Equivalents. Cybernetics And Systems Analysis, 3(43): 315-320, DOI: 10.1007/ s10559-007-0051-9. Retrieved September, 2012 from http://www.springerlink.com/content/ $16874062 \mathrm{u} 13028 \mathrm{pn} /$.

Grygorkiv, V., Bujak, L., and Pauchok, V. (2008). Modeling the Interaction of Legal and Shadow Economies at the Macro Level. Cybernetics and Systems Analysis, 1: 127-136.

Grygorkiv, V., and Verstiak, A. (2008). Modeling Prices in an Ecologically Balanced Economy with Nonlinear Linkages. Economic Cybernetics, 3-4(51-52): 48-54.

Gryhorkiv, V., and Yakutova, O. (2004). Modeling of Optimal Economic Growth Based on Environmental-Economic Balance and VAT. Economic Cybernetics, 5-6: 24-31.

Jeffers, J.N.R. (1987). Ecological Modeling: Shortcomings and Perspectives. Economic-Ecological Modeling. Elsevier Science Publishers. B. V. (North-Holland): IIASA, p. 36-48.

Lyashenko, I. (1999). Economic Modeling and the Models of Sustainable Development. Kiew: Higher School, p. 82-90.

Lyashenko, I. (2010). The Modeling of Economic, Ecological and Social Processes: A Tutorial. Kiev: Kiev publishing center "Kyiv University", p. 320.

Lyashenko, I., Mikhalevich, M., and Uteulyev, N. (1994). The Methods of Ecological-Economic Modeling. Nukus: Bylym, p. 234.

Mikhalevich, M., and Sergienko, I. (2005). The Modeling of Transformation Economics: Models, Methods, Information Technology. Kyiv: Naukova Dumka, p. 670.

Onishchenko, A. (2011). Modeling of Ecological and Economic Interaction in the Course of the Kyoto Protocol. Poltava: Poltava Writer, p. 398.

Petrov, A., Pospelov, I., and Shananin, A. (1996). The Experience of Mathematical Modeling of the Economy. M.: Energoatomizdat, p. 544.

United Nations Conference on Environment and Development (UNCED). Rio de Janeiro, 3-14 June, 1992. Retrieved September, 2012 from http://www.un.org/geninfo/bp/enviro.html.

\section{SĄVEIKOS TARP EKOLOGINIŲ IR EKONOMINIŲ PROCESŲ MODELIAVIMAS}

\author{
Mariia GRYGORKIV \\ Vasyl GRYGORKIV \\ Andrii VERSTIAK \\ Jurijaus Fedkovičiaus Černivcių nacionalinis universitetas, Ukraina
}

Santrauka. Itvairūs ekonominės visuomenès struktūros modeliai pristatomi akcentuojant jų poveikị ekologinès ir ekonominès sąveikos procesams. Modeliai priklauso simuliacinių modelių, apibūdinančių ekonominès struktūros rodiklių, kainų ir taršos dinamiką, tipui. Modeliai gali būti naudojami tiriant ekologinių ir ekonominių sistemų bei jų socialinès padèties struktūrą ir pasekmes.

Reikšminiai žodžiai: ekonominė visuomenès struktūra, simuliaciniai modeliai, kainos, ekologinè ir ekonominé sistemos, ekologinè ir ekonominè sąveika. 